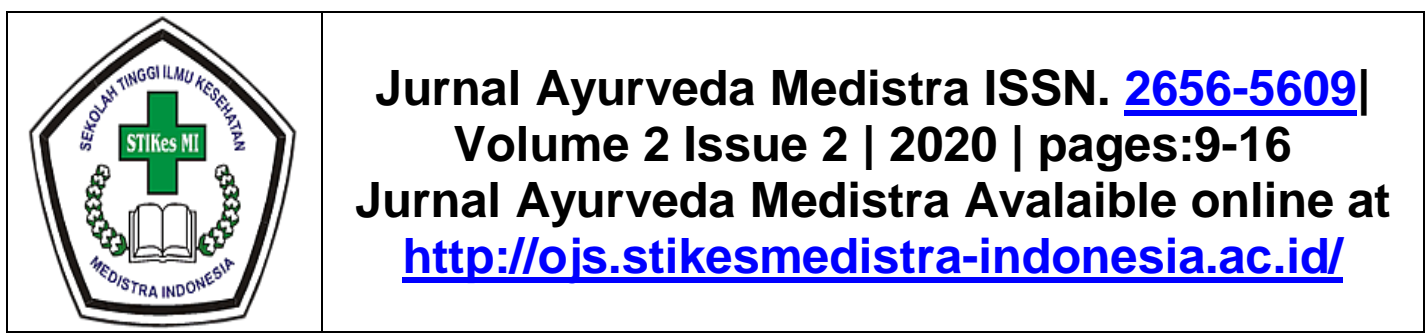

\title{
PENGARUH FLUSHING NACL 0,9\% TERHADAP KEJADIAN FLEBITIS PADA PASIEN YANG TERPASANG KATETER INTRAVENA PERIFER
}

\author{
Siti Aminah¹, Rikadefi \\ ${ }^{1}$ Bachelor Science in nursing study program of Budi Luhur Cimahi Instutite of Health Sciences \\ ${ }^{2}$ Bachelor Science in nursing study program of Budi Luhur Cimahi Instutite of Health Sciences \\ ${ }^{1}$ st.amie63@gmail.com
}

\begin{abstract}
Background: Phlebitis incidents become indicator of hospital minimum service quality with standard occurrence $<1.5 \%$. If the phlebitis incidents are not managed as soon as possible, it is able to make complication and primary blood stream infectious seriously and fatal which causes the sepsis or death. The incidents can be managed by implementing nursing intervention standard operation procedure well such as one of the procedure by flushing NaCL 0,9\%. Purpose: The aims of the research is to identify the flushing effect of NaCL, 0,9\% against phlebitis incidents on clients applying perifer intravenous catheter. Method: research method used queasy experimental with non randomize control group pretest posttest design. This research done was at Zam-zam ward in RSUD AI IHSAN West Java Bandung Regency. Research samples were as many as 46 respondents who applied perifer intravenous catheter that divided became two groups of 23 respondents who were in intervention group and 23 respondents in control group. Phlebitis scale used PPI surveillance forms. Result: Test result of Man Whitney was obtained $p$ value $=0,001<\alpha(0,05)$ that showed there was the difference phlebitis incident in each of intervention and control groups. Conclusion: There was the effect of $\mathrm{NaCL}$ 0,9\% flushing against the phlebitis, consequently it is advisable to establish standard operating procedures flushing in the effort to prevent the occurrence of phlebitis.
\end{abstract}

Keywords: Flushing $\mathrm{NaCl} 0,9 \%$, phlebitis, perifer intravenous catheter

\begin{abstract}
Abstrak
Latar belakang: Kejadian flebitis menjadi indikator mutu pelayanan minimal rumah sakit dengan standar kejadian $<1,5 \%$. Kejadian flebitis ini bila tidak segera ditangani dapat mengakibatkan komplikasi lebih serius yaitu Infeksi Aliran Darah Primer (IADP) yang berakibat fatal karena bisa menyebabkan sepsis atau kematian. Kejadian flebitis dapat dicegah dengan cara mematuhi standar prosedur tindakan keperawatan salah satunya adalahflushing $\mathrm{NaCl} 0,9 \%$. Tujuan penelitian ini untuk mengetahui pengaruh flushing $\mathrm{NaCl}$ $0,9 \%$ terhadap kejadian flebitis pada pasien yang terpasang kateter intravena perifer. Metode: Penelitian quasi eksperimen dengan desain non randomize control group pretest posttest design. Penelitian dilakukan di Ruang Zam-zam RSUD Al Ihsan. Sampel penelitian ini pasien yang terpasang kateter intravena perifer berjumlah 46 responden yang terdiri dari 23 responden kelompok intervensi dan 23 responden kelompok kontrol. Pengukuran flebitis menggunakan format survellans PPI. Hasil: Hasil uji Man Whitney diperoleh Pvalue $=0,001<\alpha(0,05)$ yang menunjukkan adanya perbedaan kejadian plebitis pada kelompok perlakuan dan kontrol. Kesimpulan: Ada pengaruh flushing Nacl 0,9\% terhadap kejadian flebitis. Oleh karena itu disarankan untuk menetapkan standar prosedur operasional flushing dalam upaya pencegahan kejadian flebitis.
\end{abstract}

Kata kunci: Flushing $\mathrm{NaCl}$ 0,9\%, flebitis, kateter intravena perifer 


\section{Pendahuluan}

Infeksi terkait pelayanan kesehatan atau HAls (Healthcare Associated Infection) menjadi salah satu indikator mutu kinerja rumah sakit terhadap kualitas pelayanan yang diberikan. Angka kejadian HAls secara umum di dunia cukup tinggi yaitu 7,1\% per tahun atau dari 190 juta pasien yang dirawat. Angka kematian akibat infeksi nosokomial $(H A / s)$ ini cukup tinggi yaitu 1 juta per tahunnya. Survei yang dilakukan WHO tahun 2010 terhadap 28 rumah sakit di Amerika dan Eropa menunjukkan insiden infeksi nosokomial (HA/s) 13 - 20 kejadian dari 1000 hari pasien dirawat dengan rincian 83\% pasien dengan infeksi VAP, 97\% infeksi saluran kemih, $81 \%$ infeksi aliran darah perifer/flebitis. ${ }^{(1)}$ Adapun insiden HAls yang paling banyak di ruang perawatan adalah infeksi akibat komplikasi pemasangan kateter intravena perifer yaitu flebitis.

Flebitis adalah keadaan inflamasi pada vena, yang dapat disebabkan oleh iritasi jenis materi kateter intravena, iritasi kimia yang berasal dari substansi tambahan dan obat-obatan yang diberikan secara intravena dan posisi anatomis kateter intravena perifer yang ditandai dengan nyeri, edema, eritema, dan meningkatnya suhu kulit di sekitar vena, dan kemerahan pada jalur vena Infusion Nurses Society. ${ }^{(2)}$

Kejadian flebitis mencapai $10 \%$ di Asia Tenggara. Angka kejadian flebitis tertinggi terdapat di negara-negara berkembang seperti India (27,9\%), Iran (14,2\%), Malaysia $(12,7 \%)$, Filipina $(10,1 \%)$ dan Indonesia (9,8\%). Berdasarkan data CDC Tahun 2017 kejadian flebitis menempati urutan keempat sebagai infeksi yang sering ditemukan pada pasien selama menjalani masa perawatan di rumah sakit. ${ }^{(3)}$

Menurut Pasaribu, presentase kejadian flebitis di Indonesia terjadi di beberapa rumah sakit yaitu di RS Cipto Mangunkusumo Jakarta (53,8\%), RSUD Sardjito Yogyakarta (27,19\%), RSUD Purworejo (18,8\%), RSCM Jakarta (17,11\%), RSUD Prof. Dr. Aloe Saboe Gorontalo (7,51\%), RSUD Dr. Soetomo (14,06\%), RS AR Bunda Prabumulih $(12,25 \%) .4)$

Menurut Duerink, et all, insiden HAls di beberapa rumah sakit di Jawa Barat berdasarkan laporan komite PPI masingmasing rumah sakit yaitu RSUD Cibabat Cimahi (1,7\%), RS Al Islam Bandung (0,3\%), RSUD Slamet Garut (20\%) dan RSUP Hasan Sadikin (1,8\%). Sedangkan berdasarkan data surveillans PPI di RSUD Al Ihsan insiden HAls tahun 2017 adalah $4,34 \%$. $^{(5)}$

Pemasangan Kateter Vena Perifer (PVC) merupakan metode paling sederhana dan paling sering digunakan untuk pemberian obat, cairan parenteral, dan produk darah. Diperkirakan bahwa sebanyak $85 \%$ pasien di rumah sakit memerlukan Peripheral Venous Line (PVL) dengan $70 \%$ pasien memerlukan PVC. Namun PVC dikaitkan dengan komplikasi mekanik dan infeksi. Komplikasi ini meliputi thrombosis, dislodgment, ekstravasasi, kebocoran, flebitis dan pembentukan parut. ${ }^{(6)}$

Dari berbagai macam komplikasi terkait terapi intravena, flebitis menjadi salah satu komplikasi yang paling sering muncul dan apabila disertai dengan pembentukan 
thrombus,

flebitis

dinamakan

thrombophlebitis. Kejadian flebitis bila tidak segera ditangani dapat mengakibatkan komplikasi yang lebih serius yaitu Infeksi Aliran Darah Primer (IADP) yang berakibat fatal karena dapat menyebabkan sepsis atau bahkan kematian. ${ }^{(7,8)}$

Tanda klinis flebitis termasuk nyeri, kemerahan, bengkak, vena mengeras, atau purulensi dari daerah insersi.(9) Faktor-faktor yang mempengaruhi flebitis adalah faktor kimia yang meliputi obat-obatan dan jenis cairan infus, faktor bakteri yang meliputi teknik aseptik dan teknik sterilitas alat, serta faktor mekanik yang meliputi teknik insersi, kondisi pasien, kondisi vena, ukuran dan bahan kanul. ${ }^{(10)}$

Kejadian flebitis ini dapat dicegah dengan cara mematuhi standar prosedur tindakan keperawatan yang berlaku diantaranya adalah dilakukan pembilasan (flushing) menggunakan $\mathrm{NaCl} \quad 0,9 \%$. Flushing merupakan pembilasan yang dilakukan pada kateter intravena yang bertujuan untuk menjaga kateter tetap berfungsi baik dan mempertahankan kelancaran aliran normal dengan interval yang sudah ditentukan Infusion Nurses Society. ${ }^{11,12)}$

Ada berbagai strategi untuk mencegah dan mengurangi komplikasi terkait PVC, yaitu dengan mengoptimalkan kelancaran infus melalui pembilasan (flushing), hal ini dilakukan untuk mencegah oklusi dan infiltrasi. Saat ini hanya sedikit yang mengetahui status pembilasan (flushing). Tanda klinis dari oklusi adalah kerusakan kateter, dan flushing sangat disarankan untuk memastikan kateter tetap berfungsi dengan baik. Oleh karena itu indikator flushing ini dipengaruhi jenis cairan, metode, dan volume yang sesuai untuk diterapkan pada semua jenis kateter intravena. ${ }^{(6)}$

Berdasarkan hasil studi pendahuluan observasi dan wawancara bulan Januari 2017 pada pasien yang terpasang kateter intravena perifer di ruang Zamzam, didapatkan data bahwa dari 10 pasien yang terpasang kateter intravena perifer (infus) ada 3 pasien flebitis atau 30\% dan 7 pasien tidak flebitis atau 70\%. Angka kejadian flebitis ini melebihi Standar Pelayanan Minimal (SPM) menurut Depkes, yaitu $\leq$ 1,5\%.(13) Hal ini kemungkinan disebabkan oleh tindakan flushing yang belum dilakukan secara maksimal, karena beranggapan bahwa tindakan flushing masih bersifat terapi bukan pencegahan dan juga belum dibuat standar operasional prosedur. Peran perawat dalam perawatan kateter intravena perifer (infus) terutama tindakan flushing sangat penting karena dengan melakukan setiap shift dinas diupayakan dapat mengurangi angka kejadian flebitis.

Dari uraian di atas peneliti tertarik untuk meneliti dan melihat langsung isu-isu yang berkaitan dengan pembilasan (flushing) yang dilakukan pada kateter intravena perifer untuk menggambarkan bukti yang ada terkait dengan manfaat flushing $\mathrm{NaCl}$ $0,9 \%$ dengan judul penelitian "Pengaruh Flushing $\mathrm{Nacl}$ 0,9\% Terhadap Kejadian Flebitis Pada Pasien Yang Terpasang Kateter Intravena Perifer"

\section{Metode}

Jenis Penelitian ini menggunakan metode penelitian Quasi Experiment Non Randomize Control Group Pretest Posttest 
Design. Penelitian dilakukan di Ruang Zamzam RSUD Al Ihsan Provinsi Jawa Barat pada bulan April-Mei Tahun 2018. Sampel pada penelitian adalah pasien yang terpasang kateter intravena perifer 46 orang yang terdiri dari 23 kelompok intervensi dan 23 kelompok kontrol.Teknik pengambilan sampel menggunakan purposive sampling. Kriteria sampel dalam penelitian ini:

1. Kriteria inklusi :
a) Pasien sadar dan bersedia menjadi responden.
b) Pasien dewasa yang terpasang kateter intravena perifer
c) Pasien dirawat 24 jam - 4 hari
d) Pasien dirawat di ruang Zamzam

2. Kriteria eksklusi :
a) Pasien dengan penyakit gagal jantung dan gagal ginjal
b) Pasien yang mendapatkan obat kemotherapi
c) Pasien geriatri ( $>65$ tahun), bayi dan anak

Alat ukur kejadian flebitis yang digunakan yaitu format survellans PPI tentang monitoring pasien terpasang kateter intravena perifer dengan hasil ukur skor derajat flebitis menurut Daugherty. ${ }^{(14)}$

Obeservasi kondisi area insersi dalam waktu 24 - 72 jam. Pada kelompok intervensi diberikantindakan flushing sesuai SPO dengan memasukkan cairan $\mathrm{NaCl}$ 0,9\% melalui infus dengan cara dibolus minimal 1-2 $\mathrm{ml}$ per 12 jam atau sebelum dan sesudah memberikan terapi intravena selama minimal 72 jam (3 hari).Kelompok kontrol dalam penelitian ini tidak mendapatkan perlakuan apapun. Analisa data dilakukan secara univariate dan bivariat dengan uji Man whitney.

\section{Hasil}

Tabel 1. Karakteristik Responden

\begin{tabular}{lc}
\hline \multicolumn{1}{c}{ Variabel } & $\mathbf{n ~ ( \% )}$ \\
\hline Umur & $43,20+12,12$ \\
\hline Jenis Kelamin & \\
Laki-laki & $13(28,3 \%)$ \\
Perempuan & $33(71,7 \%)$ \\
\hline Lokasi Infus & \\
Chepalic & $35(76,1 \%)$ \\
Metacarpal & $11(23,9 \%)$ \\
\hline Antibiotik & \\
Ya & $21(45,7 \%)$ \\
Tidak & $25(54,3 \%)$ \\
\hline
\end{tabular}

Berdasarkan table 1 diketahui dari 46 pasien yang terpasangan kateter intravena perifer rata-rata berusia 43,20 Tahun, berjenis kelamin perempuan $71,7 \%$, lokasi infus chepalic $76,1 \%$ tidak diberikan antibiotic $54,3 \%$.

Tabel 2. Gambaran Kejadian Flebitis Pada Pasien yang Terpasang Kateter Intravena Perifer Pada KelompokKontrol dan Intervensi

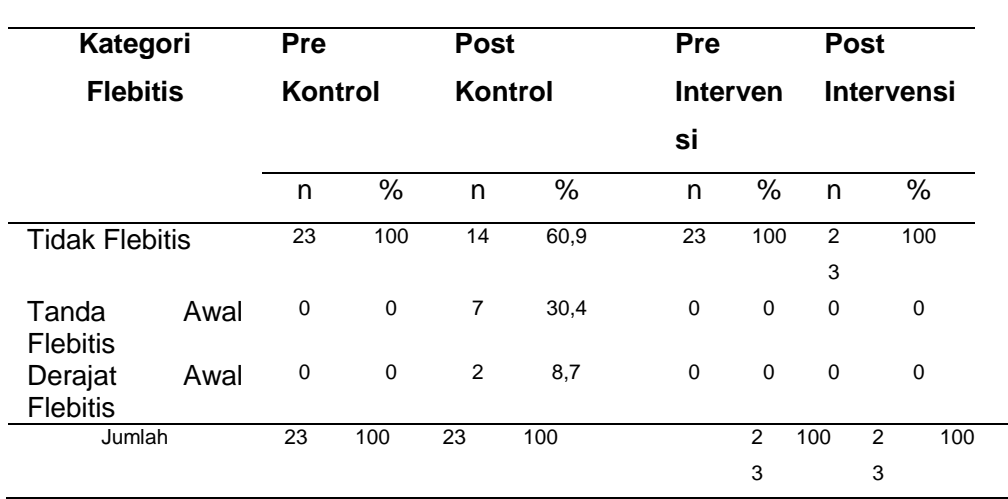


Hasil analisis yang dilakukan pada kelompok kontrol maupun intervensi pada awal pemasangan kateter intravena perifer seluruh responden yaitu 23 orang (100\%) tidak terjadi flebitis.Pada kelompok kontrol sesudah pemasangan kateter intravena perifer sebagian besar responden yaitu 14 orang $(60,9 \%)$ tidak terjadi flebitis, hampir setengahnya yaitu 7 orang $(30,4 \%)$ menunjukkan tanda awal flebitis dan sebagian kecil yaitu 2 orang $(8,7 \%)$ menunjukkan derajat awal flebitis. Pada kelompok intervensi setelah pemasangan kateter intravena perifer seluruhnya tidak terjadi phlebitis.

Tabel 3. Pengaruh Flushing Nacl 0,9\% Terhadap Kejadian Flebitis Pada Pasien Yang Terpasang Kateter Intravena Perifer Di Ruang Zamzam RSUD Al Ihsan Provinsi Jawa Barat.

\begin{tabular}{lcccc}
\hline $\begin{array}{c}\text { Kejadian } \\
\text { Flebitis }\end{array}$ & $\begin{array}{c}\text { Mean } \\
\text { Rank }\end{array}$ & $\begin{array}{c}\text { Sum of } \\
\text { Rank }\end{array}$ & $\begin{array}{c}\text { P } \\
\text { Value }\end{array}$ & $\mathbf{n}$ \\
\hline $\begin{array}{l}\text { Kelompok } \\
\text { Intervensi }\end{array}$ & 19,00 & 437,00 & & 23 \\
$\begin{array}{l}\text { Kelompok } \\
\text { Kontrol }\end{array}$ & 28,00 & 644,00 & 0,001 & 23 \\
\hline
\end{tabular}

Hasil analisis didapatkan mean rank pada kelompok intervensu adalah 19,00 dan sum of rank 437,00 lebih rendah kejadian phlebitis dibandingkan kelompok yang kontrol dengan nilai mean rank 28,00 dan sum of rank 644,00 . Hasil uji statistik dengan uji Mann Whitney diperoleh $p$ value: 0,001 . (<a: 0,05), maka Ho ditolak, dengan demikian dapat disimpulkan bahwa terdapat perbedaan yang signifikan antara kelompok intervensi yang dilakukan flushing $\mathrm{NaCl}$ $0,9 \%$ dengan kelompok kontrol yang tidak dilakukan flushing $\mathrm{NaCl}$ 0,9\% terhadap kejadian flebitis di Ruang Zamzam RSUD AI Ihsan Provinsi Jawa Barat.

\section{Pembahasan}

Data hasil penelitian pada kelompok kontrol setelah pemasangan kateter intravena perifer hampir setengahnya yaitu 7 orang $(30,4 \%)$ menunjukkan tanda awal flebitis dan sebagian kecil yaitu 2 orang $(8,7 \%)$ menunjukkan derajat awal flebitis.

Hal yang dapat mempengaruhi terjadinya flebitis pada kelompok kontrol pada penelitian ini adalah faktor kimia yaitu pemberian obat-obatan dan jenis cairan infus, diantaranya pemberian obat antibiotik yang dimasukkan bersamaan dengan obat lain tanpa dilakukan pembilasan dulu dan hal lainnya kondisi pasien dengan usia ratarata $>40$ tahun, kondisi vena yang terlalu kecil dan ukuran kateter intravena yang kurang sesuai.

Jika dikaitkan antara hasil penelitian dengan teori yang ada bahwa kejadian flebitis pada kelompok kontrol ini disebabkan oleh reaksi kimia yang terjadi akibat interaksi obat yang kurang sesuai dengan cairan infus yang diberikan selama terpasang kateter intravena perifer, karena pemberian obat melalui selang intravena memiliki resiko terjadinya flebitis yang diakibatkan oleh pencampuran dan kecepatan pemberian obat yang tidak sesuai. Selain itu sebab mekanik yang terjadi pada saat insersi serta pemilihan ukuran kateter intravena yang tidak sesuai dan belum diberlakukannya proses pembilasan (flushing) $\mathrm{NaCl} 0,9 \%$ pada semua pasien yang terpasang kateter 
intravena perifer terutama yang mendapatkan terapi intravena.

Hasil analisis yang dilakukan dari jumlah responden pada kelompok intervensi sebanyak 23 orang, diketahui bahwa pada pre dan post flushing $\mathrm{NaCl} 0,9 \%$ seluruh responden yaitu 23 orang (100\%) tidak terjadi flebitis. Hal ini memberikan gambaran keberhasilan dari intervensi yang dilakukan oleh peneliti dan membuktikan bahwa tindakan flushing $\mathrm{NaCl}$ 0,9\% ini bermanfaat dalam proses perawatan pasien yang terpasang kateter intravena perifer (infus) dan dapat menjaga kepatenan aliran infus serta mencegah terjadinya komplikasi pada pemasangan kateter intravena perifer, yaitu kejadian flebitis.

Hal tersebut sejalan pula dengan penelitian Keogh, S. et all pada tahun 2014 yang menyatakan ada berbagai strategi untuk mencegah dan mengurangi komplikasi terkait pemasangan kateter intravena perifer, yaitu dengan mengoptimalkan kelancaran infus melalui pembilasan (flushing), hal ini dilakukan untuk mencegah oklusi dan infiltrasi. Tanda klinis dari oklusi adalah kerusakan kateter, dan flushing sangat disarankan untuk memastikan kateter tetap berfungsi dengan baik. Oleh karena itu indikator flushing ini dipengaruhi jenis cairan, metode, dan volume yang sesuai untuk diterapkan pada semua jenis kateter intravena. ${ }^{(6)}$

Hasil analisis berdasarkan uji Mann Whitney diperoleh nilai Pvalue : 0,001 menunjukkan bahwa terdapat perbedaan yang significant antara kelompok intervensi dan kelompok kontrol, dimana tindakan flushing $\mathrm{NaCl}$ 0,9\% yang dilakukan dapat mengurangi angka kejadian flebitis. Hasil penelitian ini membuktikan bahwa adanya kesesuain antara teori dengan hasil penelitian sebelumnya. Tindakan flushing ini membatu dalam upaya pencegahan kejadian flebitis pada pasien yang terpasang kateter intravena perifer, terutama pada pasien yang mendapatkan cairan infus hipertonik dan mendapatkan obat-obatan injeksi lebih dari satu macam obat dengan masa perawatan lebih dari 3 hari.

Penelitian Uma, Devi \& Anthony tahun 2016 menyatakan intermittent flushing normal saline dua kali dalam satu hari efektif dalam menjaga kepatenan jalur intravena. Terdapat perbedaan yang significant pada kondisi kepatenan infus antara kelompok kontrol dengan kelompok intervensi. Bahwa pada kelompok intervensi flushing normal saline dapat menjaga kepatenan kateter intravena.(15) Selain itu Goossens dan Godelieve menjelaskan bahwa flushing dan locking berfungsi menjaga dinding vena terbebas dari sumbatan karena sisa obat, bekuan darah dan untuk mencegah pembentukan gumpalan intraluminal atau kolonisasi kateter untuk periode waktu bila kateter tidak digunakan. Komposisi cairan yang di gunakan dalam flushing yaitu cairan Natrium Klorida $(\mathrm{NaCl}) \quad 0,9 \%$ yang merupakan larutan isotonis dan memiliki konsentrasi zat terlarut yang sama dengan konsentrasi plasma serta dapat digunakan untuk mengganti volume ekstrasel.(16)

\section{Kesimpulan}

Ada pengaruh tindakan flushing $\mathrm{NaCl}$ $0,9 \%$ terhadap kejadian flebitis pada pasien yang terpasang kateter intravena perifer. Hasil ini bisa menjadi acuan bagi pengambil 
kebijakan khususnya untuk membuat standar prosedur operasional flushing $\mathrm{NaCl}$ $0,9 \%$ dalam upaya pencegahan kejadian flebitis.

\section{Ucapan Terima Kasih}

Penulis mengucapkan terima kasih kepada institusi RSUD Al Ihsan Bandung dan semua pihak yang berkonstribusi dalam proses penelitian.

\section{Daftar Pustaka}

1. World Health Organization (Who). Report on the Burden of Endemic Health Care-Associated Infection Worldwide. [Internet]. WHO Library Cataloguing-in-Publication Data. 2011. Available from: http://apps.who.int/iris/bitstream/handle /10665/80135/9789241501507_eng.pd f;jsessionid=D68E072A0ECFA54942D B99DD9D32CFBD? sequence $=1$

2. Potter PA, Perry AG. Fundamentals of Nursing/ Nursing Skills Online Version 2.0 [Internet]. Elsevier Science Health Science Division; 2010. Available from: https://books.google.co.id/books?id=ffv fQQAACAAJ

3. O'Grady NP, Alexander M, Burns LA, Dellinger EP, Garland J, Heard SO, et al. Guidelines for the prevention of intravascular catheter-related infections. J Keperawatan Kebidanan Stikes Dian Husada Mojokerto [Internet]. 2015;7 No 2(October):11. Available from: http://linkinghub.elsevier.com/retrieve/p ii/S019665531100085X\%5Cnpapers3:/ /publication/doi/10.1016/j.ajic.2011.01. 003

4. Sutomo. Hubungan Perawatan Infus
Dengan Terjadinya Flebitis Pada Pasien Yang Terpasang Infus. J Keperawatan Kebidanan - Stikes Dian Husada Mojokerto [Internet]. 2015;7(2):57-61. Available from: https://jurnalonline.Ippmdianhusada.ac. id/index.php/jkk/article/view/72

5. Duerink DO, Farida $H$, Nagelkerke NJD, Wahyono $\mathrm{H}$, Keuter M, Lestari ES, et al. Preventing nosocomial infections: improving compliance with standard precautions in an Indonesian teaching hospital. J Hosp Infect [Internet]. 2006 Sep 1 [cited 2018 Sep 17];64(1):36-43. Available from: http://www.ncbi.nlm.nih.gov/pubmed/1 6822581

6. Keogh S, Marsh N, Higgins N, Davies K, Rickard C. A time and motion study of peripheral venous catheter flushing practice using manually prepared and prefilled flush syringes. J Infus Nurs. 2014;

7. Berman A, Snyder SJ, Kozier B, Erb GL, Levett-Jones T, Dwyer T, et al. Kozier \& Erb's Fundamentals of Nursing Australian Edition [Internet]. Pearson Higher Education AU; 2014. Available from: https://books.google.co.id/books?id=w MWaBQAAQBAJ

8. Rosdahl CB, Kowalski MT. Textbook Of Basic Nursing Alih Bahasa Widiarti dan Tampubolon, Buku Ajar Keperawatan Dasar. 10Th ed. Jakarta: EGC; 2012.

9. Ray-Barruel G. INFECTION PREVENTION: PERIPHERAL INTRAVENOUS CATHETER ASSESSMENT AND CARE. Aust Nurs 
midwifery J [Internet]. 2017 Mar [cited 2018 Sep 17];24(8):34. Available from: http://www.ncbi.nlm.nih.gov/pubmed/2 9261251

10. Society IN, Corrigan A, Gorski L, Hankins J, Perucca R, Alexander M. Infusion Nursing - E-Book: An Evidence-Based Approach [Internet]. Elsevier Health Sciences; 2011. Available from: https://books.google.co.id/books?id=cj vH3ZzUyvgC

11. International Nosocomial Infection Control Consortium (INICC) Care Bundles to Prevent Central and Peripheral Line-Related Bloodstream Infections [Internet]. January 1. 2017 [cited 2018 Mar 23]. Available from: http://www.inicc.org/media/docs/2017INICCBSIPreventionGuidelines.pdf

12. Gorski L, Hadaway L, Hagle ME, McGoldrick M, Orr M, Doellman D. Infusion Therapy Standards of Practice. J Infus Nurs. 2016;39(1S):S1-159.

13. Departemen Kesehatan RI. Pedoman Pencegahan dan Pengendlian Infeksi di
Rumah Sakit dan Fasilitas Pelayanan Kesehatan Lainnya. Direktorat Jenderal Pelayanan Medik; 2008. 1-156 p.

14. Dougherty $L$ et all. Standards for infusion therapy The RCN IV Therapy Forum The RCN IV Therapy Forum [Internet]. Royal college of nursing. 2010 [cited 2018 Jan 7]. p. 6-10. Available from: http://www.areac54.it/public/royal college of nursing standards for infusion therapy.pdf

15. Uma $\mathrm{T}$, Devi MB, Mary Anthony. Effectiveness of intermittent normal saline flushing in maintaining the patency of intravenous cannula. Manipal J Nurs Heal Sci. 2016;2(January):0-4.

16. Goossens GA. Flushing and Locking of Venous Catheters: Available Evidence and Evidence Deficit. Nurs Res Pract [Internet]. 2015;2015:1-12. Available from:

http://www.hindawi.com/journals/nrp/2 015/985686/ 